\title{
Intratumoral recombinant GM-CSF-encoding virus as gene therapy in patients with cutaneous melanoma
}

\author{
Michael J. Mastrangelo, ${ }^{1}$ Henry C. Maguire Jr., ${ }^{1}$ Laurence C. Eisenlohr, ${ }^{2}$ Carol E. Laughlin, ${ }^{2}$ \\ Claude E. Monken, ${ }^{1}$ Peter A. McCue, ${ }^{3}$ Albert J. Kovatich, ${ }^{3}$ and Edmund C. Lattime ${ }^{1,2}$ \\ Departments of ${ }^{1}$ Medicine, ${ }^{2}$ Microbiology and Immunology, and ${ }^{3}$ Pathology, Anatomy, and Cell Biology, \\ Jefferson Medical College of Thomas Jefferson University, Philadelphia, Pennsylvania 19107.
}

\begin{abstract}
Seven immunocompetent, revaccinated patients with surgically incurable cutaneous melanoma underwent treatment of dermal and/or subcutaneous metastases with twice-weekly intratumoral injections of escalating doses $\left(10^{4}-2 \times 10^{7}\right.$ plaque-forming units (PFU)/lesion; $10^{4}-8 \times 10^{7} \mathrm{PFU} /$ session) of a vaccinia/GM-CSF recombinant virus for 6 weeks. Patients with stable or responding disease were maintained on treatment until tumor resolution or progression. Systemic toxicity was infrequent, dose-related, and limited to mild flu-like symptoms that resolved within 24 hours. Local inflammation, at times with pustule formation, was consistently seen with doses of $\geq 10^{7}$ PFU/lesion. Chronically treated lesions showed a dense infiltration, with CD4 ${ }^{+}$and $\mathrm{CD}^{+}$ lymphocytes, histiocytes, and eosinophils. All seven patients developed an antivaccinia humoral immune response 14-21 days following revaccination. Despite the presence of these antivaccinia antibodies, the reporter gene was expressed, as judged by the development of anti- $\beta$-galactosidase antibodies in all patients. Passenger cytokine gene function was evidenced by the presence of virally encoded GM-CSF mRNA at injection sites both early (weeks 1 and 5) and late (week 31) in the course of treatment. Eosinophilia at treatment sites indicated that physiologically significant levels of functional cytokine were generated. However, there were no changes in the total number of peripheral white blood cells or in the numbers or percentages of polymorphonuclear leukocytes, monocytes, or eosinophils. GM-CSF was not detected in the sera. The two patients with the largest tumor burdens failed to respond even at treatment sites. Three patients had mixed responses, with regression of treated and untreated dermal metastases and progression of disease elsewhere. One patient had a partial response, with regression of injected and uninjected regional dermal metastases. Residual melanoma was excised, rendering the patient disease free. One patient with only dermal metastases confined to the scalp achieved a complete remission. Sequential administration of escalating doses of a GM-CSF recombinant vaccinia virus is safe, effective at maintaining passenger gene function, and can induce tumor regression.
\end{abstract}

Key words: Vaccinia; recombinant GM-CSF; intratumoral; gene therapy, melanoma.

$\mathrm{T}$ The demonstration by Prehn and Main ${ }^{1}$ of functionally specific tumor-associated antigens (Ags) that could be targeted to effect tumor regression provided a scientific foundation for the pursuit of active specific immunization as a cancer treatment. Early clinical trials of active specific tumor immunotherapy used whole tumor cells as immunogens almost exclusively. Autologous tumor cells display by definition not one but all of the potential Ag epitopes expressed by the host tumor, both tumor rejection-related and tumor rejection-irrelevant. The historical development of tumor cell-based vaccines has been reviewed by Mastrangelo et al. ${ }^{2}$ When used alone, cell-based vaccines demonstrated little ability to induce tumor regression or to prolong disease-free

Received June 26, 1998; accepted November 1, 1998.

Address correspondence and reprint requests to Dr. Michael J. Mastrangelo, Division of Medical Oncology, Jefferson Medical College, Suite 1024, Curtis Building, 1015 Walnut Street, Philadelphia, PA 19107-5099. (C) 1999 Stockton Press 0929-1903/99/\$12.00/+0 survival. The addition of adjuvants (bacillus CalmetteGuérin, Corynebacterium parvum, and Detox®, Ribi Immuno Chem Research, Hamilton, Mont), haptens (keyhole limpet hemocyanin, and dinitrophenyl), and immunomodulators (cyclophosphamide) enhanced efficacy; still, only a minority of patients benefited.

Advances in basic immunology led to an appreciation of the cascade of molecular events integral to the development of an immune response. Requisite is an array of cytokines that provide the costimulatory signals important for T-lymphocyte activation. We and others hypothesized that enrichment of the cytokine milieu at the vaccination site would enhance the acquisition of immunity. Reasoning that higher and perhaps more effective cytokine levels could be sustained at the immunization site by local production rather than by local or systemic injection, tumor cells or fibroblasts genetically engineered to produce the molecule(s) of interest were included in vaccine preparations. The demonstration by Golumbek et $\mathrm{al}^{3}$ that immunization with tumor cells engineered to secrete Interleukin(IL)-4 could induce 
Figure 1. Schematic of the strategy for generating the GM-CSF-expressing $\mathrm{VV}$ recombinant. The top fragment represents the 5.1-kb "J" fragment resulting from a HindIII digest of the VV genome. The vaccinia TK gene resides on this fragment. Homologous recombination into the TK gene using the pSC65 vector, into which the GM-CSF gene has been inserted, disrupts the TK gene and is predicted to replace the $5.1-\mathrm{kb}$ fragment with two fragments of $\sim 1.6$ and $8.2 \mathrm{~kb}$. The $\beta$-gal gene, which is used to distinguish true recombinants from spontaneous TK mutants, is inserted as well.

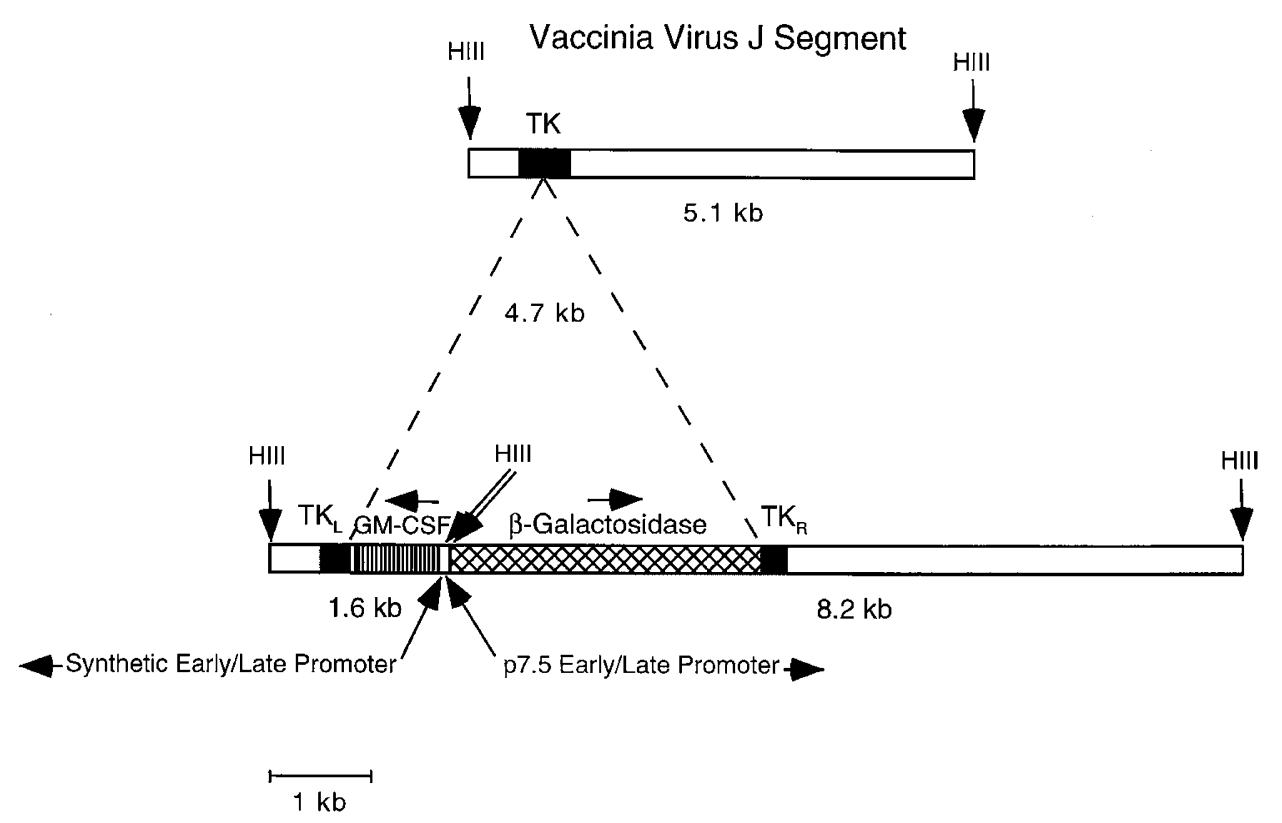

regression of an established syngeneic renal cell cancer in mice launched many clinical trials, the available results of which were recently reviewed. ${ }^{4}$ Some tumor regressions have been noted primarily in patients with melanoma.

Although studies in murine models and early clinical data support the hypothesis that enrichment of the cytokine milieu at the immunization site can result in tumor rejection/regression, the use of in vivo gene transfer techniques in the clinic is severely limited by the requirement that an autologous tumor be available, removed, grown in tissue culture, transfected with the gene(s) of interest, etc. We propose that this cumbersome procedure can be circumvented by the use of a recombinant virus (RV) to insert genes of interest into tumors in vivo so that cytokines are produced in situ, thereby enhancing tumor immunogenicity and the acquisition of antitumor immunity.

We report here on the use of vaccinia virus (VV) as a vector for the transfer and expression of GM-CSF cDNA to melanoma cells in vivo by direct intratumoral (i.t.) injection. Toxicity was minimal with twice-weekly injections of escalating doses of RV. Reporter gene $(\beta$-galactosidase $(\beta$-gal $))$ expression and passenger cytokine gene (GM-CSF) function could be maintained over a protracted period despite the presence of antivaccinia antibody (Ab). Most often, injected metastases regressed; in some patients uninjected lesions regressed as well.

\section{MATERIALS AND METHODS}

\section{Vaccinia/GM-CSF RV}

Human GM-CSF-producing vaccinia recombinant was generated using standard techniques. ${ }^{5,6}$ The wild-type (wt) virus used in the preparation of the recombinant was derived from the New York City Board of Health strain of vaccinia (Centers for Disease Control, Atlanta, Ga). The full-length cDNA for GM-CSF was obtained from the American Type Culture Collection (Manassas, Va) (pCSF-1, no. 39754). The pSC65 vector used for generation of RV was provided by Dr. Bernard Moss (National Institute of Allergy and Infectious Diseases, Bethesda, Md). The GM-CSF gene was cloned first into the EcoRI site of pBluescript II SK (Stratagene, La Jolla, Calif) and subsequently into the SalI and BglII sites of pSC65. This plasmid was then transfected by calcium phosphate precipitation into CV-1 monkey kidney cells that had been infected 2 hours previously with a low multiplicity of non-RV. The plasmid is designed to facilitate homologous recombination into the vaccinia thymidine kinase (TK) gene (Fig 1). Recombinants were selected in 143B (human osteosarcoma, TKnegative) cells in the presence of 5-bromo- 2 '-deoxyuridine. The $\beta$-gal gene was included in the plasmid as a reporter gene. Following three rounds of selection, the virus was plaqued to confirm that a pure recombinant stock had been obtained. Southern blot analysis of HindIII-digested DNA from purified virus confirmed that the plasmid had recombined in the intended location. Northern blot analysis of cells infected with the recombinant in the presence of cycloheximide showed a mRNA species that hybridized strongly with the ${ }^{32} \mathrm{P}$-labeled GM-CSF DNA extracted from the original pCSF-1 plasmid. The size $(\sim 1$ kilobase $(\mathrm{kb}))$ was as predicted. Western blot analysis using polyclonal rabbit anti-human GM-CSF from Genzyme (Cambridge, Mass) demonstrated a heavily stained band at $\sim 24 \mathrm{kDa}$ in supernatants of vaccinia/GM-CSF-infected cells, matching the molecular mass of mature GM-CSF. An assay for biological activity was performed with the GMCSF-dependent Mo7e cell line using recombinant GM-CSF as a standard. The infection of $10^{6} 143 \mathrm{~B}$ cells (with a multiplicity of 10 plaque-forming units (PFU)/cell) generated $\sim 10^{5} \mathrm{U}$ of GM-CSF or $0.1 \mathrm{U} /$ cell (Fig 2). (By comparison, $\sim 2 \times 10^{7} \mathrm{U}$ are administered systemically daily for the treatment of neutropenia.) By these criteria, the virus was judged to be the desired product. 


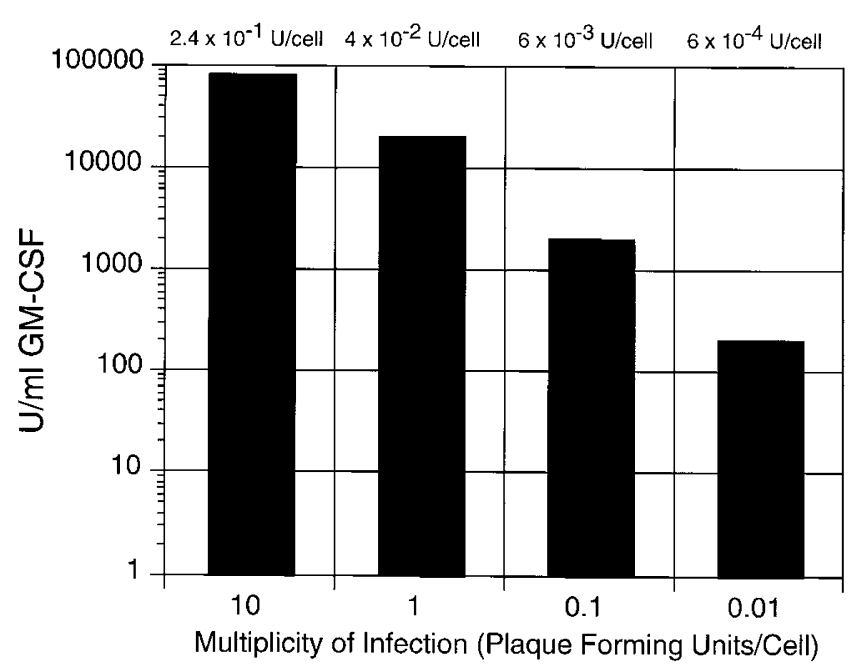

Figure 2. Biological activity of the supernatants associated with vaccinia/GM-CSF-infected cells. The 143B cells were infected with vaccinia/GM-CSF or nonrecombinant vaccinia at $10,1,0.1$, and $0.01 \mathrm{PFU} / \mathrm{cell}$. After 18 hours, the supernatants were harvested and centrifuged to remove any cells or debris before ultraviolet irradiation to eliminate infectious virus. Supernatants were then diluted 10-fold and tested for the ability to support the growth of Mo7e cells (which require GM-CSF). Pure recombinant GM-CSF (Genetics Institute, Cambridge, Mass), also diluted 10-fold, was used as a standard. The proliferation of the Mo7e cells was measured with 3-(4,5-dimethylthiazol-2-yl)-2,5-diphenyl tetrazolium bromide.

Clinical-grade material was produced under contract by DynCorp (Rockville, Md). The final product was vialed at $1.75 \times 10^{7} \mathrm{PFU}$ in $0.1 \mathrm{~mL}$.

\section{Patient population}

Seven patients with histologically documented and surgically incurable melanoma were treated. All were judged to be immunocompetent as evidenced by a positive cutaneous delayed-type hypersensitivity response to dinitrofluorobenzene (DNFB) after DNFB sensitization. The clinical characteristics of these patients are summarized in Table 1. Only one patient (patient 3) was $<60$ years of age. Six of seven patients had prior treatment, and five of these patients had been aggressively treated with combination chemotherapy. Only patient 7

Table 1. Patient Population

\begin{tabular}{|c|c|c|c|}
\hline Patient & Age/Sex & Metastatic sites & Prior treatment \\
\hline 1 & $81 / F$ & Dermal, LNs & Radiation \\
\hline 2 & 68/M & S.C., LNs, lungs & BCDT, taxol \\
\hline 3 & $32 / F$ & Dermal, breast & $\begin{array}{l}\text { Radiation, BCDT, } \\
\text { DCV + IL- } \\
2+\text { IFN, taxol }\end{array}$ \\
\hline 4 & $61 / F$ & Dermal, S.C., LNs, lungs & BCDT, IFN \\
\hline 5 & $71 / F$ & Dermal, LNs & $\begin{array}{l}\text { Limb perfusion, } \\
\text { GP100, MART- } \\
\text { 1, IL-12, BCDT }\end{array}$ \\
\hline 6 & 67/M & S.C., LNs, lungs & BCDT \\
\hline 7 & $75 / \mathrm{M}$ & Dermal & None \\
\hline
\end{tabular}

had intact and clinically uninvolved regional lymph nodes (LNs).

\section{Overall treatment plan}

Eligible patients were revaccinated (day 0) percutaneously with the wt virus, and the vaccination site was evaluated visually on day 4 to confirm that a "major reaction" was in progress. Intralesional therapy commenced on day 4 and was repeated twice weekly with dose escalations based on the local (erythema/inflammation) and systemic (clinical symptoms, physical signs, and clinical laboratory values) toxicity from the preceding injections. Toxicity was graded using the National Cancer Institute common toxicity criteria.

The induction phase of treatment lasted $\sim 6$ weeks. Stable and responding patients were continued on treatment until disease resolution or progression. Doses ranged from $10^{4}$ to $2 \times 10^{7} \mathrm{PFU} /$ lesion and $10^{4}$ to $8 \times 10^{7} \mathrm{PFU} /$ treatment session. Both pretreatment vaccination and the modest starting dose were dictated by uncertainty regarding the virulence of the RV and consequently by patient safety concerns. Doses were escalated in each patient to compensate for the anticipated development of antivaccinia immunity.

Injection sites were protected throughout by an occlusive dressing. During the maintenance phase of treatment, patients 3 through 7 received short courses of low-dose $\left(3 \times 10^{6}\right.$ U/day $\times 5$ days) IL-2 to assess the effect of this cytokine on established immunity to DNFB. (There was no change over baseline in the DNFB challenge response, nor was there a discernible effect on visible metastases.)

\section{Gene product expression and host-infiltrating cells at treatment and control sites}

Punch biopsies $(5 \mathrm{~mm})$ were performed before treatment, after the first treatment, and later in the course of therapy using conventional, sterile, dermatological surgical techniques. The biopsies were subdivided, and those reserved for reverse transcriptase-polymerase chain reaction (RT-PCR) assay were snap-frozen in liquid nitrogen and stored at $-70^{\circ} \mathrm{C}$ until use. Histochemistry for cell subset identification and hematoxylin and eosin $(\mathrm{H} \& \mathrm{E})$ staining for morphology were performed on formalin-fixed tissue.

RT-PCR for vaccinia-encoded (VAC) GM-CSF $m R N A$. Total RNA was isolated from snap-frozen melanoma biopsies and was quantitated spectrophotometrically before the RT step. cDNA synthesis was performed using $10 \mu \mathrm{g}$ of total RNA, random primer (Life Technologies, Gaithersburg, Md), and RT buffer in diethyl pyrocarbonate-thromboxane water. The reaction mixture was incubated at $65^{\circ} \mathrm{C}$ for 10 minutes and subsequently maintained at $4^{\circ} \mathrm{C}$. To the mixture, $10 \mathrm{mM}$ dithiothreitol (Life Technologies); $0.5 \mathrm{mM}$ each of deoxyadenosine triphosphate, deoxycytidine triphosphate, deoxyguanosine triphosphate, and deoxyribosylthymine triphosphate (Life Technologies); and $500 \mathrm{U}$ Moloney murine leukemia virus RT (Life Technologies) were added to achieve a final reaction volume of $50 \mu \mathrm{L}$. Samples were incubated at $37^{\circ} \mathrm{C}$ for 1 hour and then heated to $95^{\circ} \mathrm{C}$ for 5 minutes. For amplification by PCR, $5 \mu \mathrm{L}$ of each cDNA was then added to MicroAmp reaction tubes (Perkin Elmer, Norwalk, Conn) containing PCR buffer; $0.2 \mathrm{mM}$ each of deoxyadenosine triphosphate, deoxycytidine triphosphate, deoxyguanosine triphosphate, and deoxyribosylthymine triphosphate; $1.25 \mathrm{U}$ AmpliTaq DNA Polymerase (Perkin Elmer); $\mathrm{MgCl}_{2}$ concentrations determined to be optimal in our laboratory for each primer pair (final concentrations of $1.5-4.0 \mathrm{mM}$ ); and $0.5 \mathrm{uM}$ 
each of the appropriate primer pairs in a final volume of $50 \mu \mathrm{L}$. The primer pairs used in this study included $\beta$-actin $\left(5^{\prime}\right.$ tga-cgg-ggt-cac-cca-cac-tgt-gcc-cat-cta-3'/5' -cta-gaa-gca-ttgcgg-tgg-acg-atg-gag-gg-3') and primers designed to amplify vaccinia-encoded GM-CSF that included flanking regions of the viral plasmid (5'-aag-ctc-gaa-gtc-gac-ggt-atc-g-3'/5' -cgatga-agg-aca-gtt-ctt-tcc-aga-c- $\left.3^{\prime}\right)$. Primers were obtained from the Kimmel Cancer Center Nucleotide Facility (Thomas Jefferson University). $\beta$-actin served as a standard for the comparison of relative mRNA expression between samples and served as a control for the RT-PCRs. PCR samples were amplified using a GeneAmp System 9600 thermocycler (Perkin Elmer). PCR products and size markers (100-base pair ladder; Promega, Madison, Wis) were separated in a $2 \%$ SeaKem GTG agarose gel (FMC BioProducts, Rockland, Me). The gel was stained with ethidium bromide and visualized and photographed under ultraviolet illumination. Electrophoresis of PCR products revealed a band corresponding to the predicted fragment size for each set of primers.

Immunohistochemical staining for cell subsets. Formalin-fixed, paraffin-embedded sections were stained to elucidate infiltrating cell subsets. ${ }^{7,8}$ Primary Abs for CD3 (clone PS1, immunoglobulin G2a (IgG2a), Novocastra, Newcastle on Tyne, UK), CD4 (clone 1F6, IgG1; Novocastra); CD8 (clone CB/144B, IgG1; Dako, Carpinteria, Calif), CD30 (clone Ber-H2, IgG1 ; Dako), CD45RO (clone UCHL1, IgG2a $;$ Dako), and CD68 (clone KP1, IgG1 $\kappa$; Dako) were used to identify $\mathrm{T}$ cells, helper/inducer $\mathrm{T}$ cells, cytotoxic $\mathrm{T}$ cells, activated $\mathrm{B}$ cells, activated $\mathrm{T}$ cells, and tissue macrophages, respectively.

\section{Serum}

Samples were obtained before revaccination, on day 4 (first i.t. vaccinia/GM-CSF treatment), and weekly thereafter. Samples were stored at $-20^{\circ} \mathrm{C}$ until needed for $\mathrm{Ab}$ or GM-CSF assays. All samples for a given patient were assayed on the same day.

\section{Humoral immunity to vaccinia and $\beta$-gal}

To measure serum titers for antivaccinia Ab, 96-well plates were coated with a $1 / 20$ dilution of vaccinia obtained from cultures of human osteosarcoma cell line 143B that had been infected for 18 hours with the CR-19 strain of VV. Following blocking with phosphate-buffered saline plus fetal calf serum, a dilution series of patient sera before and after treatment was added to the wells and incubated for 1 hour; next, the plates were washed. Serum anti-VV Abs were visualized using a peroxidase-labeled antihuman IgG heavy and light chain second reagent (Caltag, South San Francisco, Calif) and $o$ phenylenediamine substrate. Titers were read as the reciprocal serum dilution yielding $50 \%$ maximum absorbance in the assay. For $\mathrm{Ab}$ to $\beta$-gal, wells were coated with a solution of $\beta$-gal (10 $\mu \mathrm{g} / \mathrm{mL}$; Sigma, St. Louis, Mo) in place of the vaccinia described previously, and the assays were performed similarly.

\section{Serum GM-CSF levels}

To determine serum levels of GM-CSF, 96-well plates were coated with a $1 / 250$ dilution of the capture anticytokine $\mathrm{Ab}$ (BVD2-23B6; PharMingen, San Diego, Calif). Following blocking with $10 \%$ fetal calf serum in phosphate-buffered saline, serum samples were added; the wells were incubated overnight at $4^{\circ} \mathrm{C}$. Next, the plates were washed, biotinylated anti-GM-CSF Ab (BVD2-21C11; PharMingen) was added, and the reaction was developed with avidin-peroxidase $/ 2,2^{\prime}$ azinobis(3-ethylbenzothiazoline-6-sulfonic acid). The sensitivity of this assay is $3 \mathrm{ng} / \mathrm{mL}$.
Tumor regression. Both treated and control lesions were monitored (by physical examination and appropriate imaging), and the response of the tumor(s) was categorized as follows: Complete response, complete disappearance of all evident disease for $\geq 4$ weeks; partial response, decrease in the mean diameter of measured signal lesions by $\geq 50 \%$ for $\geq 4$ weeks without simultaneous growth of other masses; mixed response, regression of some lesions while other lesions progress; progressive disease, $a \geq 25 \%$ increase in the mean diameter of signal lesions and/or the development of new lesions.

Regulatory compliance. This study was approved by the Institutional Review Board and Biosafety Committee of Thomas Jefferson University. All patients provided written informed consent, and the study was conducted under the auspices of BB-IND 6486.

\section{RESULTS}

Tissue reaction, toxicity, and safety

Revaccination sites. Despite having been vaccinated previously against smallpox as children, when revaccinated with the wt virus, all patients developed major local reactions equivalent to a primary take, with bleb formation and a 2-week interval to resolution.

Treatment sites. With the vaccinia/GM-CSF RV, local toxicity consisted of inflammation of injected metastases (Fig 3). Inflammation was dose-related and was consistently found in lesions injected with $\geq 10^{7} \mathrm{PFU} /$ treatment. Serially treated metastases often became pustular. The development of inflammation in lesions newly injected but late ( $\geq 28$ days) in the course of treatment was considered clinical evidence of the ability of locally administered virus to infect cells despite the presence of antivaccinia Abs.

As has been our experience, ${ }^{9}$ before the initiation of treatment, dermal and subcutaneous (s.c.) metastases were consistently microscopically devoid of acute or chronic inflammation and T-lymphocyte infiltration (Fig 4). After $\geq 28$ days of injections of RV twice weekly, many lesions were completely necrotic, whereas others retained sufficient cellular detail to allow microscopic assessment. As anticipated, these lesions were acutely inflamed and densely infiltrated with $\mathrm{T}$ lymphocytes $\left(\mathrm{CD}^{+}\right)$of both the $\mathrm{CD} 4^{+}$and $\mathrm{CD}^{+}$subsets as well as tissue macrophages $\left(\mathrm{CD}^{+} 8^{+}\right.$) (Fig 5). T lymphocytes displaying the activation marker $\mathrm{CD} 45 \mathrm{RO}$ as well as activated $\mathrm{B}$ lymphocytes $\left(\mathrm{CD} 30^{+}\right)$were present.

Systemic toxicity. Flu-like symptoms occurred within 4-6 hours after 10 of 84 treatments $(12 \%)$ of $\geq 4 \times 10^{7}$ PFU of RV. These symptoms were mild (grade 1), responded to conservative therapy, and resolved within 24 hours. There were no treatment-related changes in the laboratory parameters defining hematological, hepatic, and renal function (data not shown).

There were no cases of autoinoculation or interpersonal transmission of either wt viruses or RVs. 


\section{PATIENT \#4}



PRE-RX

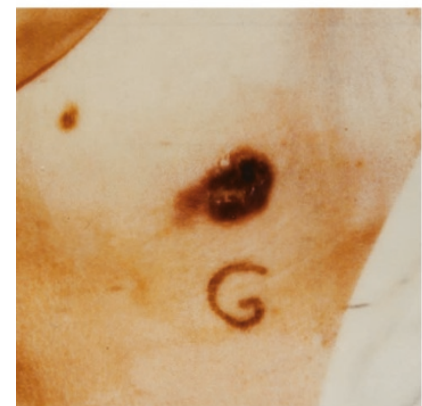

11D POST-RX

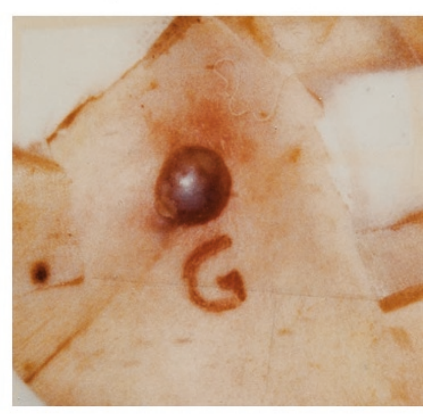

4D POST-RX

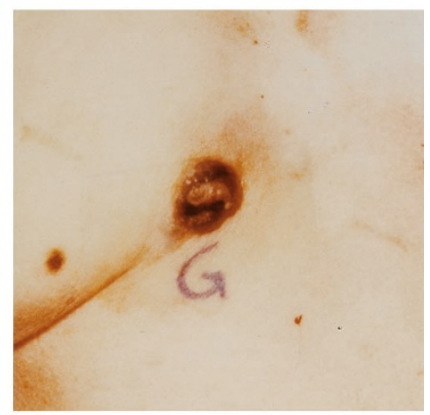

22D POST-RX
Figure 3. Local reaction to an i.t. injection of the vaccinia/GM-CSF $\mathrm{RV}$. Lesion $\mathrm{G}$ (patient 4) was polypoid, with a pretreatment diameter of 20 $\mathrm{mm}$ (a). On day $1,5 \times 10^{6} \mathrm{PFU} R V$ were injected. By day 4 , the lesion was acutely inflamed (b). Escalating doses of RV were administered twice weekly to a total dose of $60 \times 10^{6} \mathrm{PFU}$ over six sessions. With each injection, the lesion became inflamed and gradually regressed (c: day 11 , after three treatments; d: day 22, after six treatments).

\section{Humoral immune response to vaccinia}

All seven patients developed Abs to vaccinia after being revaccinated (day 0 ) and initiating (day 4 ) twice-weekly i.t. recombinant vaccinia therapy (Table 2). Titers tended to plateau at 4-6 weeks, despite continuing treatment with RV. Perhaps wt virus administered intracutaneously in an area with intact regional LNs is more effective in inducing immunity than is the i.t. injection of $\mathrm{RV}$ in a region in which, with a single exception (patient 7 ), the lymphatics were compromised. There was no correlation between $\mathrm{Ab}$ titer and tumor regression: Patient 7, low titer and complete response versus patient 2 , low titer and no response. Nor was there a correlation between the presence of intact regional $\mathrm{LNs}$ and $\mathrm{Ab}$ titer: Patients 3 and 6, absent LNs and high titers versus patient 7 , intact nodes and low titer.

\section{Reporter $\beta$-gal gene expression}

All seven patients developed a humoral immune response to the reporter gene protein product $\beta$-gal (Table $3)$. Compared with the immune response to vaccinia, the anti- $\beta$-gal $\mathrm{Ab}$ response was slower to develop (3-6 weeks) and seemingly of lesser magnitude. This likely relates to the relative doses and the timing of availability of the respective Ags. The substantial dose of vaccinia directly administered was further amplified by replication in vivo. The $\beta$-gal was generated entirely in vivo. Further, the antivaccinia response was primed by vaccination and revaccination at sites with intact regional LNs. Nonetheless, this humoral immune response is clear evidence that the reporter gene was repeatedly expressed for a protracted period. This finding should dispel concerns that the antivaccinia response would preclude development of an immune response to an unrelated $\mathrm{Ag}$ at the same site. ${ }^{10}$

\section{Passenger cytokine (VAC GM-CSF) gene function}

RT-PCR for VAC GM-CSF $m R N A$. Heavy coprecipitation of melanin pigment with RNA in the four patients with densely pigmented metastases precluded satisfactory evaluation. Data from the three evaluable patients (patients 3, 6, and 7) are presented in Figure 6. In two

\section{PATIENT \#3}

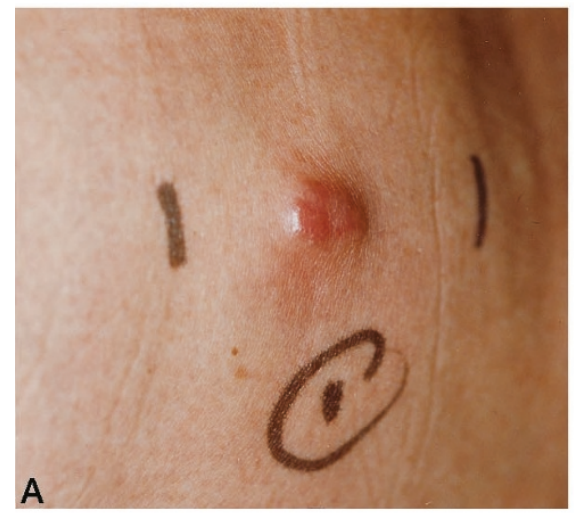

DERMAL METASTASES

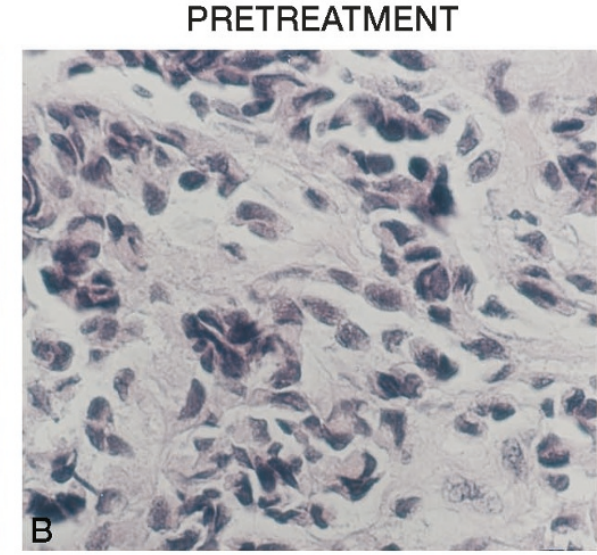

$H \& E$

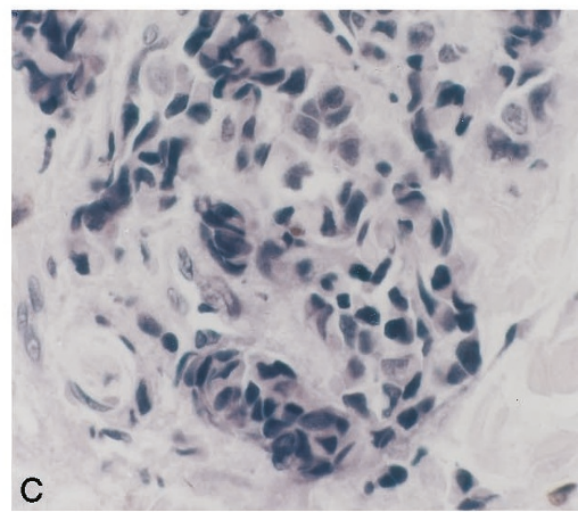

T-LYMPHOCYTES (CD3+)

Figure 4. Dermal metastasis pretreatment (patient 3). a: clinical appearance, 8-mm diameter lesion, posterior left thigh; b: H\&E stain ( $\times 400$ magnification), no inflammation; c: immunohistology ( $\times 400$ magnification), no $\mathrm{CD}^{+}$lymphocytes. 


\section{PATIENT \#3}

LESION G (TREATED, DAY +31)

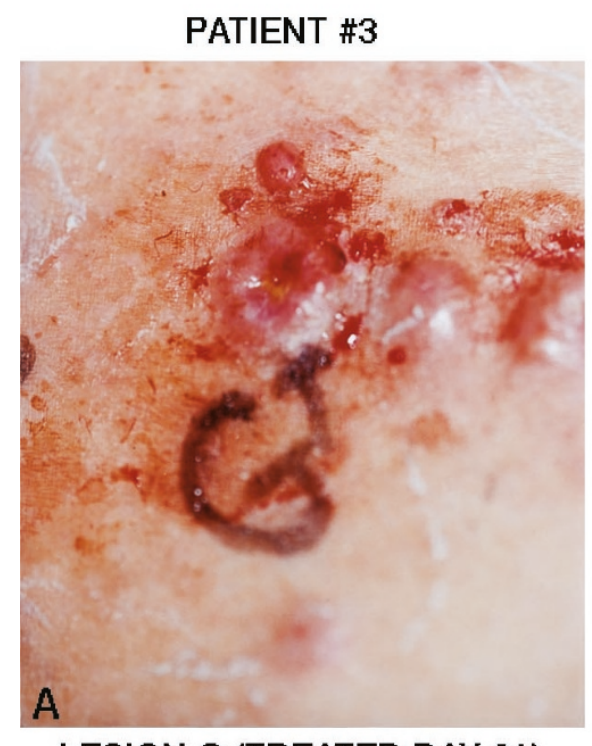

\section{LESION G (TREATED,DAY 31)}

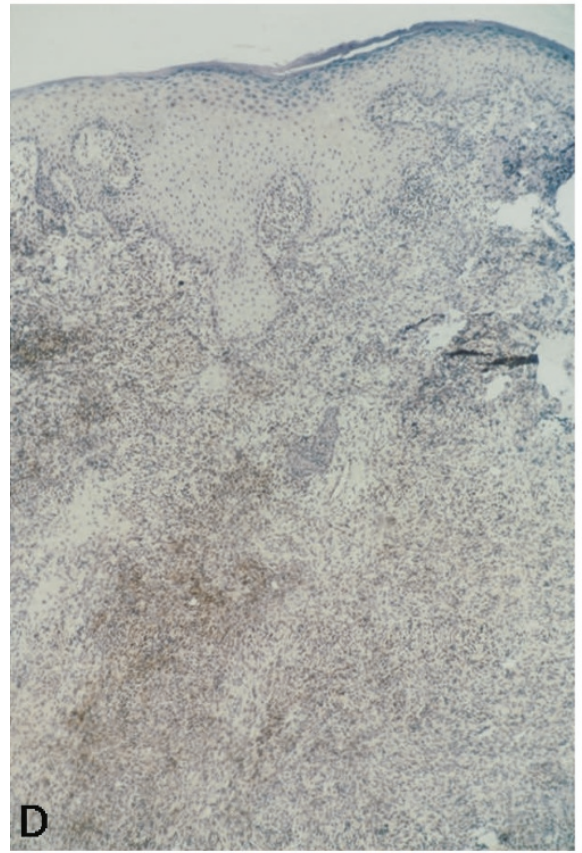

\section{HELPER T-LYMPHOCYTES} (CD4+)

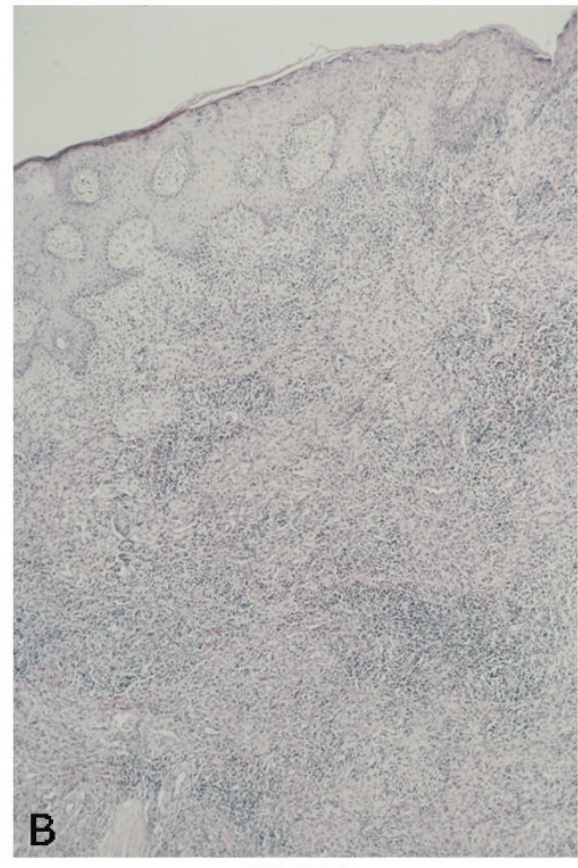

$H \& E$

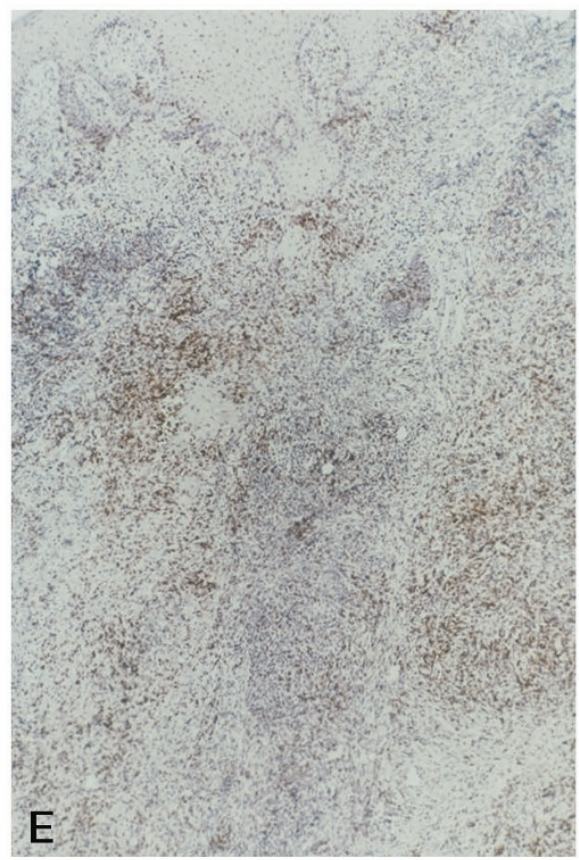

CYTOTOXIC T-LYMPHOCYTES

(CD8+)

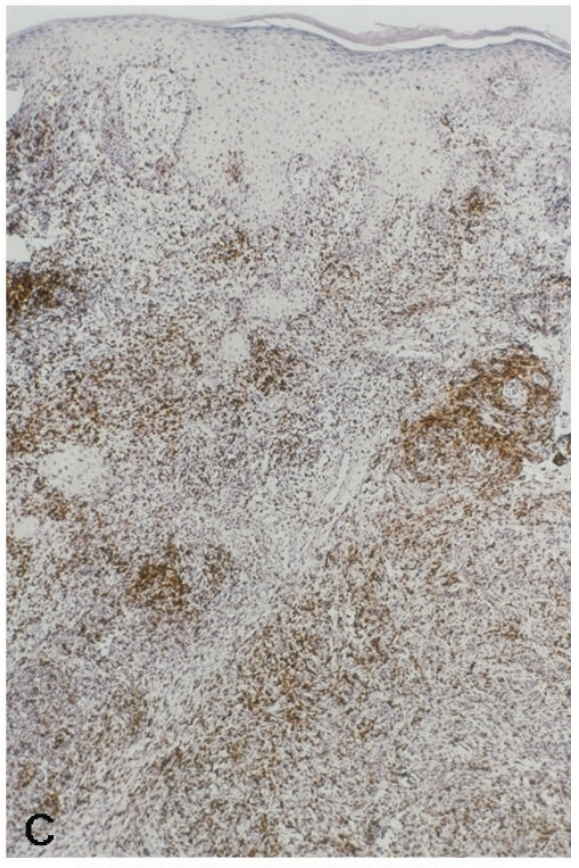

T-LYMPHOCYTES (CD3+)

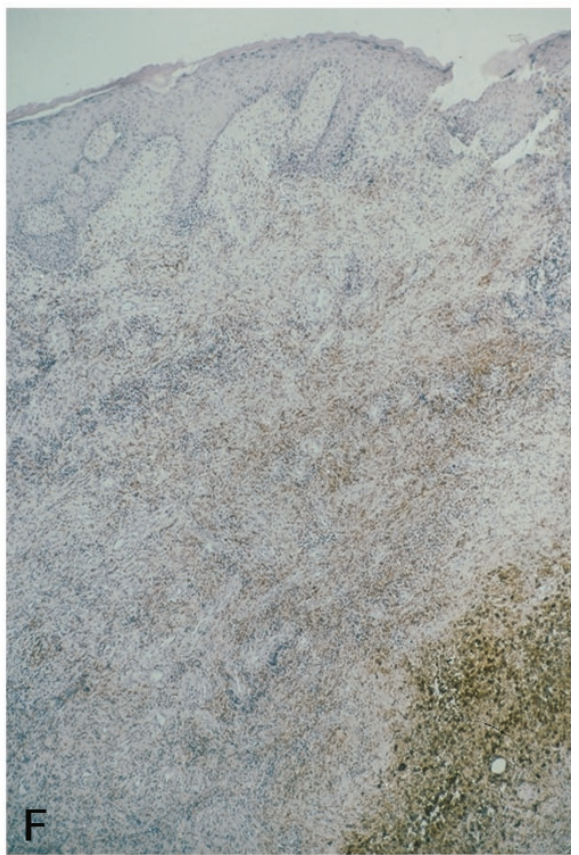

HISTIOCYTES/TISSUE MACROPHAGES

$\mathrm{KP}-1+$

Figure 5. Dermal metastasis (lesion G) treatment day 31 (patient 3). a: clinical appearance, 8-mm diameter lesion, anterior left thigh; b: H\&E stain, dense inflammatory response; c: immunohistology: dense infiltration of T lymphocytes $\left(\mathrm{CD} 3^{+}\right)$of both the helper/inducer $\left(\mathrm{CD} 4^{+}\right)(\mathbf{d})$ and cytotoxic $\left(C D 8^{+}\right)(e)$ subsets and tissue macrophages $(\mathbf{f})(\times 40$ magnification). 
Table 2. Serum Antivaccinia Ab Titers

\begin{tabular}{|c|c|c|}
\hline Patient & Day* & Titer† \\
\hline \multirow[t]{4}{*}{1} & Pretreatment & $<1: 10$ \\
\hline & 21 & $1: 180$ \\
\hline & 52 & $1: 120$ \\
\hline & 74 & $1: 180$ \\
\hline \multirow[t]{5}{*}{2} & Pretreatment & $<1: 10$ \\
\hline & 21 & $1: 50$ \\
\hline & 42 & $1: 30$ \\
\hline & 56 & $1: 20$ \\
\hline & 86 & $1: 80$ \\
\hline \multirow[t]{9}{*}{3} & Pretreatment & $<1: 10$ \\
\hline & 7 & $<1: 10$ \\
\hline & 14 & $1: 70$ \\
\hline & 21 & $1: 140$ \\
\hline & 28 & $1: 200$ \\
\hline & 35 & $1: 200$ \\
\hline & 67 & $1: 225$ \\
\hline & 95 & $1: 225$ \\
\hline & 129 & $1: 225$ \\
\hline \multirow[t]{4}{*}{4} & Pretreatment & $<1: 10$ \\
\hline & 11 & $1: 160$ \\
\hline & 25 & $1: 400$ \\
\hline & 32 & $1: 400$ \\
\hline \multirow[t]{7}{*}{5} & Pretreatment & $<1: 10$ \\
\hline & 4 & $<1: 10$ \\
\hline & 11 & $1: 10$ \\
\hline & 18 & $1: 50$ \\
\hline & 25 & $1: 25$ \\
\hline & 33 & $1: 40$ \\
\hline & 39 & $1: 200$ \\
\hline \multirow[t]{7}{*}{6} & Pretreatment & $<1: 10$ \\
\hline & 4 & $<1: 10$ \\
\hline & 11 & $>1: 300$ \\
\hline & 18 & $>1: 300$ \\
\hline & 25 & $>1: 300$ \\
\hline & 32 & $>1: 300$ \\
\hline & 39 & $>1: 300$ \\
\hline \multirow[t]{6}{*}{7} & Pretreatment & $<1: 10$ \\
\hline & 4 & $<1: 10$ \\
\hline & 12 & $1: 100$ \\
\hline & 18 & $1: 100$ \\
\hline & 26 & $1: 100$ \\
\hline & 32 & $1: 100$ \\
\hline
\end{tabular}

*Day 0 is the day patients were revaccinated with wt vaccinia. Treatment with RV was initiated on day 4.

†Titers were read as the serum dilution yielding $50 \%$ of maximum absorbance in the assay.

patients (patients 6 and 7) (Fig 6a), biopsies were obtained 18 hours after a single injection of RV (5 or $7 \times 10^{6} \mathrm{PFU} /$ lesion) on day 4 (most likely prior to the development of significant levels of antivaccinia Abs). In these same patients, biopsies were obtained at week 5 (antivaccinia Abs present), 18 hours after a single injection of 20 or $30 \times 10^{6}$ PFU of RV into a previously untreated lesion. VAC GM-CSF mRNA was found in all samples, convincingly demonstrating passenger cytokine gene function. Although this technique is semiquantitative at best and the data set is small, the results suggest that mRNA levels are lower later in the course of therapy despite the larger doses of RV administered in
Table 3. Serum Anti- $\boldsymbol{\beta}$-Gal Ab Titers

\begin{tabular}{|c|c|c|}
\hline Patient & Day* & Titer† \\
\hline \multirow[t]{6}{*}{1} & Pretreatment & $<1: 10$ \\
\hline & 6 & $<1: 10$ \\
\hline & 17 & $<1: 10$ \\
\hline & 27 & $<1: 10$ \\
\hline & 41 & $1: 200$ \\
\hline & 55 & $1: 220$ \\
\hline \multirow[t]{4}{*}{2} & Pretreatment & $<1: 10$ \\
\hline & 75 & $1: 20$ \\
\hline & 82 & $1: 30$ \\
\hline & 89 & $1: 30$ \\
\hline \multirow[t]{4}{*}{3} & Pretreatment & $<1: 10$ \\
\hline & 28 & $1: 20$ \\
\hline & 45 & $1: 30$ \\
\hline & 55 & $1: 100$ \\
\hline \multirow[t]{4}{*}{4} & Pretreatment & $<1: 10$ \\
\hline & 7 & $<1: 10$ \\
\hline & 21 & $1: 200$ \\
\hline & 28 & $1: 200$ \\
\hline \multirow[t]{7}{*}{5} & Pretreatment & $<1: 10$ \\
\hline & 1 & $<1: 10$ \\
\hline & 7 & $<1: 10$ \\
\hline & 14 & $<1: 10$ \\
\hline & 21 & $1: 10$ \\
\hline & 19 & $1: 20$ \\
\hline & 38 & $1: 75$ \\
\hline \multirow[t]{6}{*}{6} & Pretreatment & $<1: 10$ \\
\hline & 8 & $<1: 10$ \\
\hline & 15 & $<1: 10$ \\
\hline & 22 & $<1: 10$ \\
\hline & 29 & $1: 10$ \\
\hline & 36 & $1: 80$ \\
\hline \multirow[t]{5}{*}{7} & 1 & $<1: 10$ \\
\hline & 9 & $1: 20$ \\
\hline & 15 & $1: 20$ \\
\hline & 23 & $1: 40$ \\
\hline & 29 & $1: 50$ \\
\hline
\end{tabular}

*Days from the initiation of treatment with recombinant vaccinia.

†Titers were read as the serum dilution yielding $50 \%$ of maximum absorbance in the assay.

week 5. Furthermore, at a given timepoint, the quantity of mRNA may be directly related to the dose of RV administered; Patient 7, week 5: lane 3, $30 \times 10^{6} \mathrm{PFU}$ versus lane $4,20 \times 10^{6} \mathrm{PFU}$ of the vaccinia/GM-CSF recombinant. The prolonged treatment of patient 3 allowed us to further assess the inhibition of mRNA expression over time. She (Fig 6b) had been under treatment for 31 weeks at the time of biopsy and presumably had substantial antivaccinia Ab titers. Lane 1 represents a metastasis injected with a total of $35 \times 10^{6}$ PFU of RV during the 3 weeks before a biopsy that was performed 18 hours after an additional injection of $5 \times$ $10^{6} \mathrm{PFU}$ (total $40 \times 10^{6} \mathrm{PFU}$ ). The metastases represented by lanes 2 and 3 each received a single injection of $5 \times 10^{6}$ PFU of RV 18 hours before biopsy. Virusderived GM-CSF mRNA was found in all cases. However, multiple pretreatments did not seem to augment the quantity of the mRNA found (lane 1 versus lanes 2 
A

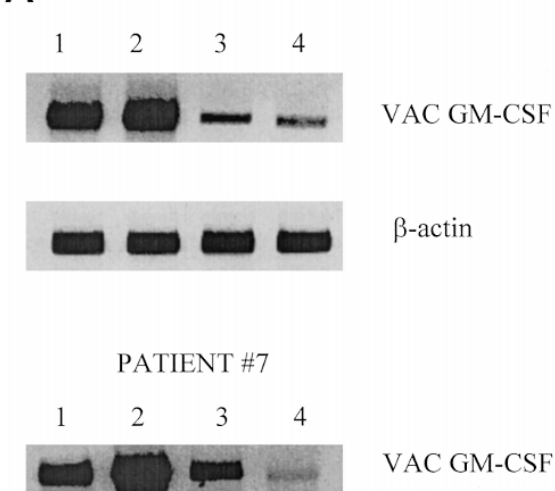

$\square \quad \beta$-actin

$1-18$ hr. biopsy (single injection week 1)

$2-18 \mathrm{hr}$. biopsy (single injection week 1)

$3-18 \mathrm{hr}$. biopsy (single injection week 5)

$4-18$ hr. biopsy (single injection week 5)

\section{B PATIENT \#3}

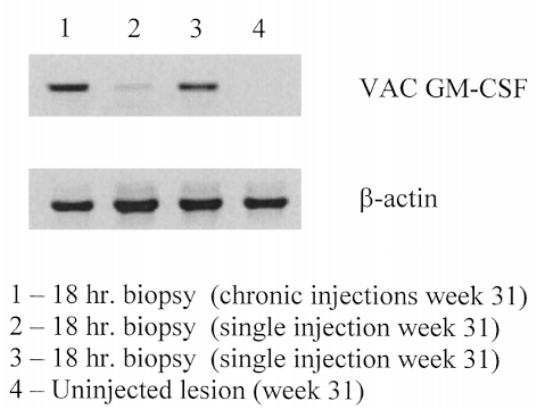

Figure 6. RT-PCR of mRNA from melanoma biopsies. Biopsies of the indicated injected and uninjected melanoma metastases from patients 6 and 7 (a) and patient 3 (b) were snap-frozen, and total RNA was prepared. RT-PCR was performed using primer pairs encoding the flanking regions of the viral plasmid insertion site (VAC GM-CSF) and for the $\beta$-actin gene as described in Materials and Methods.

and 3). Lane 4 represents an untreated lesion that was negative for virus-derived GM-CSF mRNA.

Tissue eosinophilia. GM-CSF stimulates the proliferation and differentiation of the common progenitor cell of the neutrophil, eosinophil, and monocyte. ${ }^{11}$ Increased numbers of eosinophils have been demonstrated in the cutaneous reactions that are sometimes associated with the systemic administration of GM-CSF. ${ }^{12}$ In an effort to determine whether functionally significant amounts of VAC GM-CSF were being produced at treatment sites, tumor biopsies were assessed for eosinophilia. Marked infiltration by eosinophils was seen in all (three of three) of the patients studied (Fig 7).

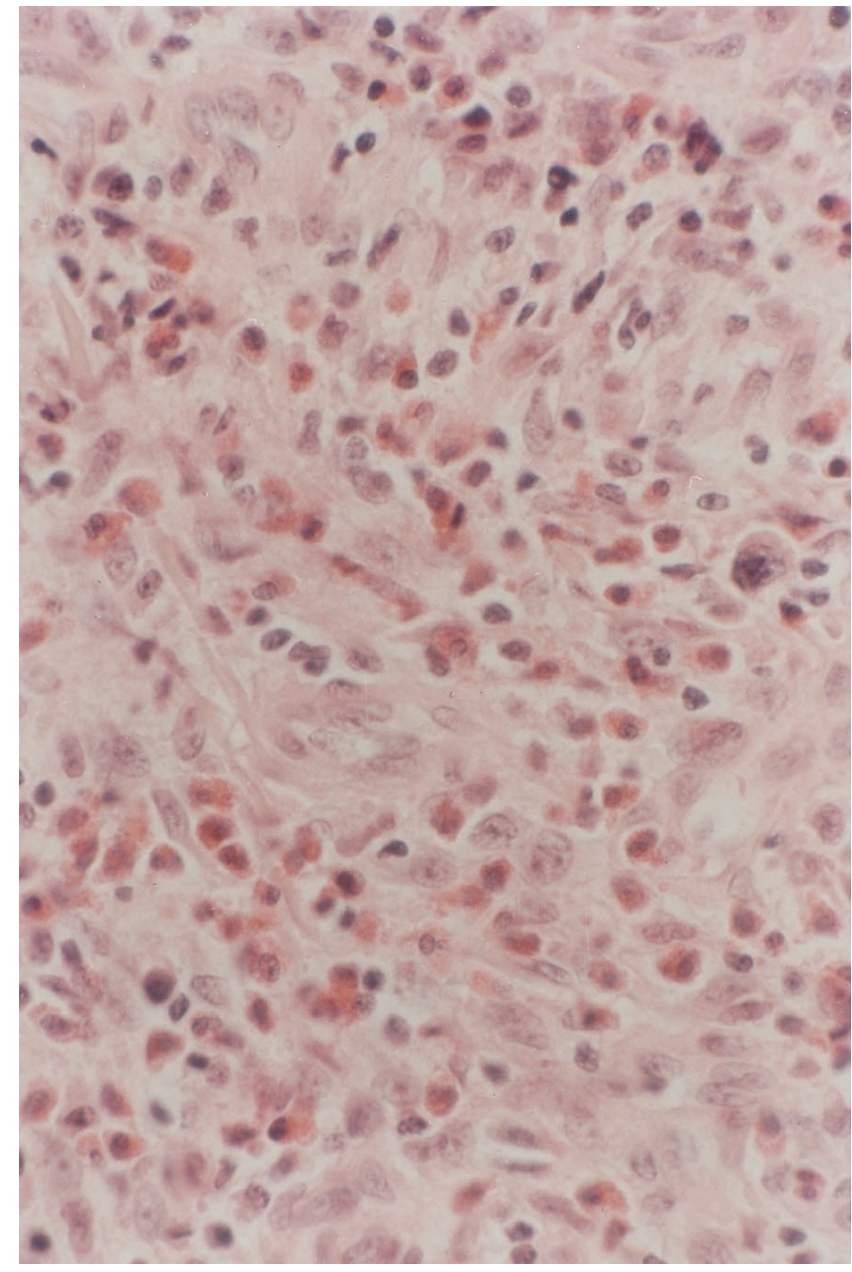

Figure 7. Dermal metastasis (lesion G) treatment day 31 (patient 3). $\mathrm{H} \& \mathrm{E}$ stain showing i.t. eosinophilia $(\times 400$ magnification).

Systemic effects of VAC GM-CSF. Total and differential peripheral white blood cell counts were performed weekly (with few omissions) throughout the course of treatment. In general, there were no consistent changes in total white blood cell counts or in the percentages or absolute numbers of polymorphonuclear leukocytes, eosinophils, or monocytes (data not shown). On three occasions, there were elevations in the total white blood cell counts that were clinically attributable to a bacterial cellulitis consequent to disruption of the integument at sites of virally induced inflammation. This leukocytosis resolved promptly with antibiotic therapy. In the first five patients, serum GM-CSF levels were monitored weekly beginning before and continuing throughout treatment. None of the 54 samples studied had detectable levels of GM-CSF ( $>3 \mathrm{ng} / \mathrm{mL}$ ) (data not shown).

\section{Tumor responses}

The responses of injected and uninjected metastases are summarized in Table 4. Two patients (patients 2 and 6) showed no evidence of regression of injected or uninjected lesions. The major clinical characteristic that 
Table 4. Tumor Response by Type of Metastasis

\begin{tabular}{|c|c|c|c|c|}
\hline \multirow[b]{2}{*}{ Patient } & \multicolumn{2}{|c|}{ Uninjected } & \multirow[b]{2}{*}{ Distant } & \multirow[b]{2}{*}{ Type } \\
\hline & Injected & Regional & & \\
\hline 2 & s.c.-no LN-no & LN-no & Lung-no & None \\
\hline 6 & s.c.-no LN-no & S.C.-no & Lung-no & None \\
\hline 1 & Dermal-yes LN-no & Dermal-yes & - & Mixed \\
\hline 4 & $\begin{array}{l}\text { Dermal-yes s.c.- } \\
\text { yes }\end{array}$ & LN-no & Lung-no & Mixed \\
\hline 5 & Dermal-yes & Dermal-yes & LN-no & Mixed \\
\hline 3 & $\begin{array}{l}\text { Dermal-yes } \\
\text { Breast-no }\end{array}$ & Dermal-yes & - & $\mathrm{PR}(6+\mathrm{mos})$ \\
\hline 7 & Dermal-yes & Dermal-yes & - & $\mathrm{CR}(4+\mathrm{mos})$ \\
\hline
\end{tabular}

distinguished these two patients from the remaining five patients was the fact that their tumor burdens were $1 \mathrm{log}$ greater than those present in the others.

Three patients (patients 1, 4, and 5) had mixed responses. These responses constituted regression of injected dermal lesions in all patients and uninjected dermal lesions in the two patients (patients 1 and 5) in whom such were present. There was regression of s.c. lesions in the one patient (patient 4) in which these were injected. Despite this favorable response in dermal and s.c. lesions, regional (patient 1) or distant (patient 5) nodal metastases and lung metastases (patient 4) slowly progressed. The response of the dermal metastases in patient 5 is illustrated in Figure 8. Injected and uninjected regional dermal metastases regressed. However, mediastinal LN metastases progressed slowly.

Patient 3 had a partial response. She was a 32-year-old female when she presented in January of 1994 with pain in her left foot. Evaluation revealed multiple bone metastases. A mass in the left inguinal area was biopsied and found to be metastatic melanoma with no known primary site. A metastatic survey revealed lung, oral, and brain metastases. The patient underwent left inguinal LN dissection and radiation therapy to the brain, left ankle, knee, and elbow. Starting in March of 1994, she received combination chemotherapy with $N, N^{\prime}$ bis(2-chloroethyl)- $N$-nitrosourea(BCNU) (carmustine), dacarbazine, cisplatin, and tamoxifen, and experienced complete disappearance of the metastases in the lung and buccal mucosa. The brain metastases regressed as well. Despite continued chemotherapy, new skin and right breast (parenchymal) metastases were detected in August of 1995. In December 1995, she was started on biochemotherapy with IL-2, interferon (IFN), vinblastine, cisplatin, and dacarbazine. Additional tumors regressed. In the spring of 1996, dermal metastases developed on the left leg (mostly thigh). Taxol administered in June of 1996 produced a mixed response, and the patient was referred for recombinant vaccinia treatment. At the initiation of treatment, parenchymal metastases were present in the right breast and dermal metastases were present on the left leg.

The i.t. treatment commenced in August of 1996. It was not until November of 1997 (15 months later) that she was convincingly free of dermal metastases, and she remained free of disease when last evaluated at day 600 (Fig 9). An uninjected lesion biopsied on day 31 was infiltrated with $\mathrm{CD} 8^{+}$lymphocytes (Fig 10) but devoid of mRNA for vaccinia TK or VAC GM-CSF gene products, nor was eosinophilia noted. Signal dermal lesions were left uninjected, and these regressed as well (e.g., Fig 11). The parenchymal breast metastases were also injected. Clinical examination and imaging proved ineffective in distinguishing treatment-related swelling from tumor progression. Thus, these lesions were surgically excised, converting the treatment-induced partial response to a surgical complete remission. Microscopically, there were foci of tumor necrosis with minimal inflammation, possibly related to the injections of recombinant vaccinia 3 months before.

Patient 7 achieved a complete response. At presentation, he was a 75 -year-old male with $\sim 24$ dermal metastases of 2-3 mm diameter at the perimeter of an area from which a primary melanoma of the scalp had been excised (Fig 12, a-c). The regional LNs were intact and clinically free of melanoma. He had no prior treatment other than for surgery. All injected and uninjected lesions regressed completely (Fig 12, d and e).

\section{DISCUSSION}

GM-CSF is a hematopoietic growth factor that has been shown to have significant effects on the immune response by (a) increasing major histocompatibility complex class II Ag expression, (b) enhancing dendritic cell maturation and migration, (c) inducing localized inflammation at the site of injection, and (d) exerting immune modulatory effects by its systemic actions on the hematopoietic cytokine network. ${ }^{13}$ Recognition of these properties led to exploration of the potential role of GM-CSF as a vaccine adjuvant.

There are several approaches to using GM-CSF as an immune-enhancing agent. Systemic administration is technically the easiest approach and has the theoretical advantage that it might affect the systemic activation of the immune system. Disadvantages are uncertainty over the amount of cytokine reaching the immunization site, the difficulty in maintaining critical levels of cytokine, and the toxicity, albeit modest, associated with systemic administration. In a preclinical immunoprophylaxis model (38C13 lymphoma, $\mathrm{C} 3 \mathrm{H} / \mathrm{HeN}$ female mice), Kwak et $\mathrm{al}^{14}$ achieved success with systemically administered GM-CSF. However, s.c. administration at the immunization site was more effective in inducing protection. Disis et $\mathrm{al}^{15}$ demonstrated that rat neu peptides inoculated with GM-CSF could elicit a strong delayedtype hypersensitivity response, whereas peptides alone were nonimmunogenic. Harris et $\mathrm{al}^{16}$ were unsuccessful in immunizing prostate cancer patients with a liposomeencapsulated prostate-specific Ag formulation. Injection of GM-CSF at immunization sites resulted in the generation of both cellular and humoral immunity. Local administration at the immunization site assures high levels of cytokine and minimizes systemic toxicity. How- 


\section{PATIENT \#5}

Medial Thigh

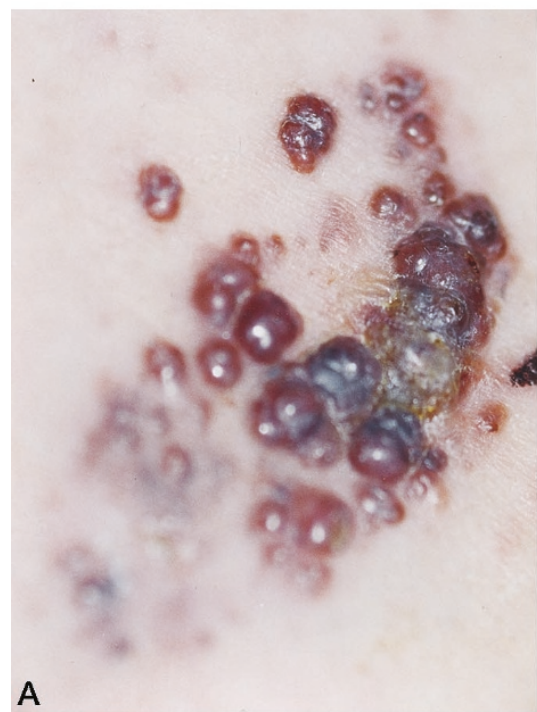

Pre-treatment



Week 24

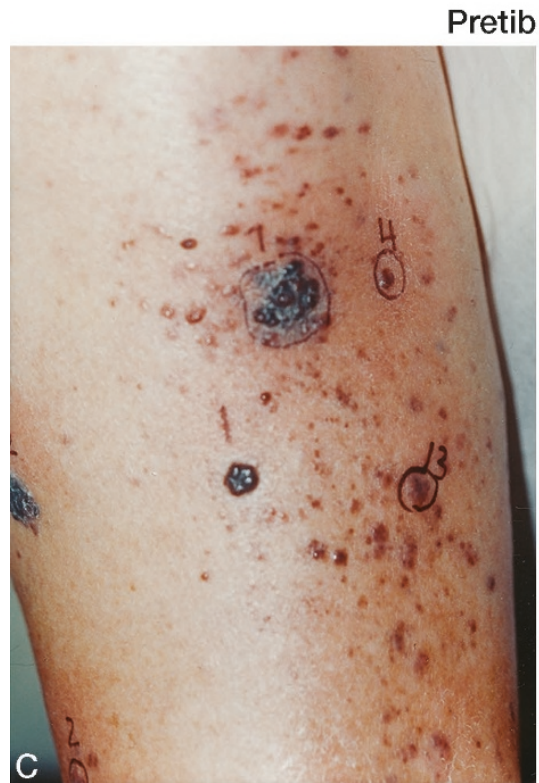

Pre-treatment

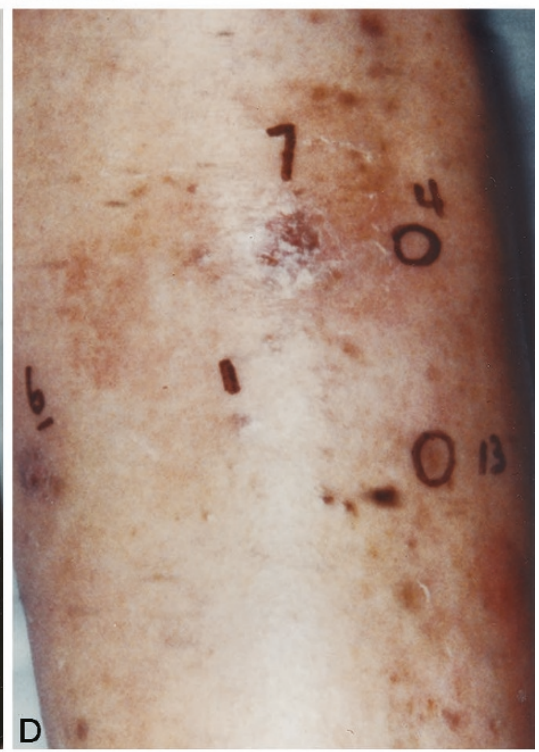

Week 24

\section{Lateral Heel}

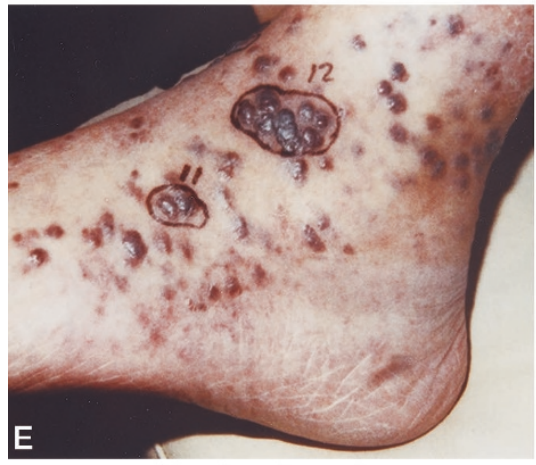

Pre-treatment

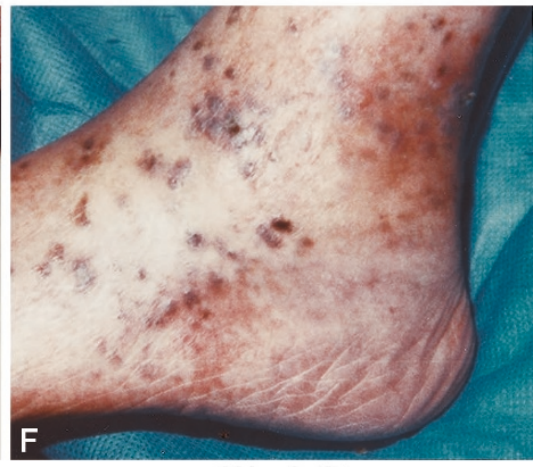

Week 24
Figure 8. Patient 5, a 71-year-old female with extensive dermal metastases of the left leg: medial thigh before treatment (a) and at week 24 (b); pretibial area before treatment (c) and week 24 (d); lateral heel before treatment (e) and at week 24 (f). Numopsied and injected. 


\section{PATIENT \# 3}

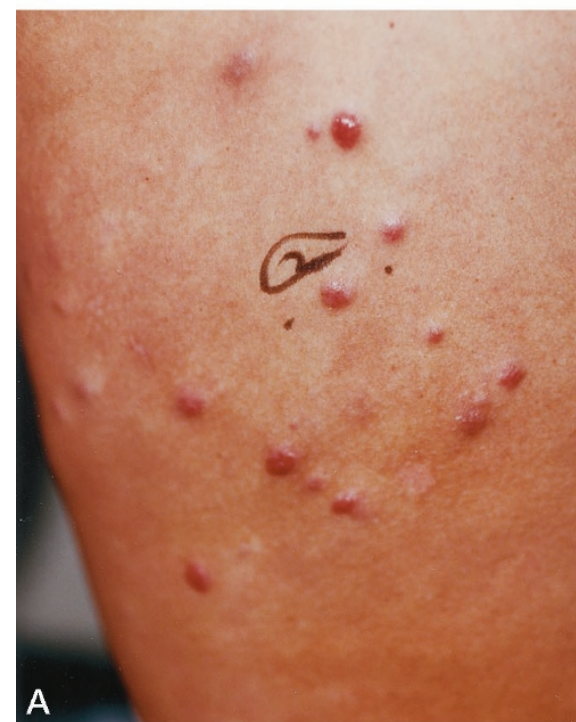

PRE-TREATMENT

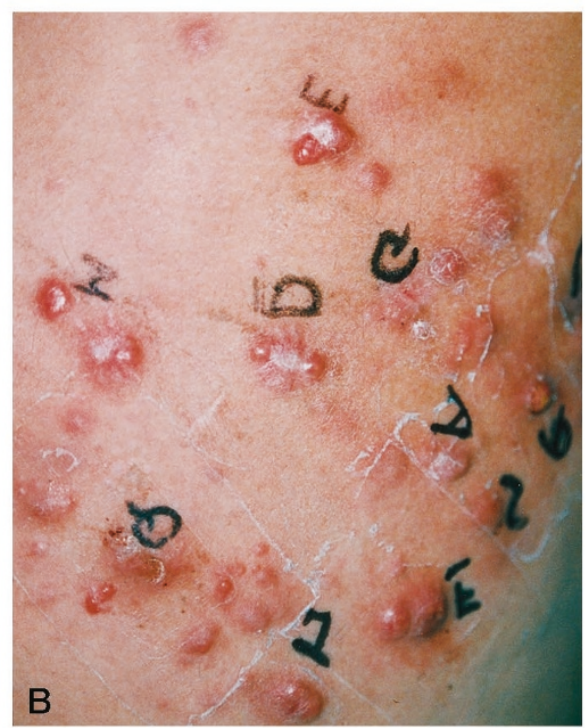

$\mathrm{DAY}+81$

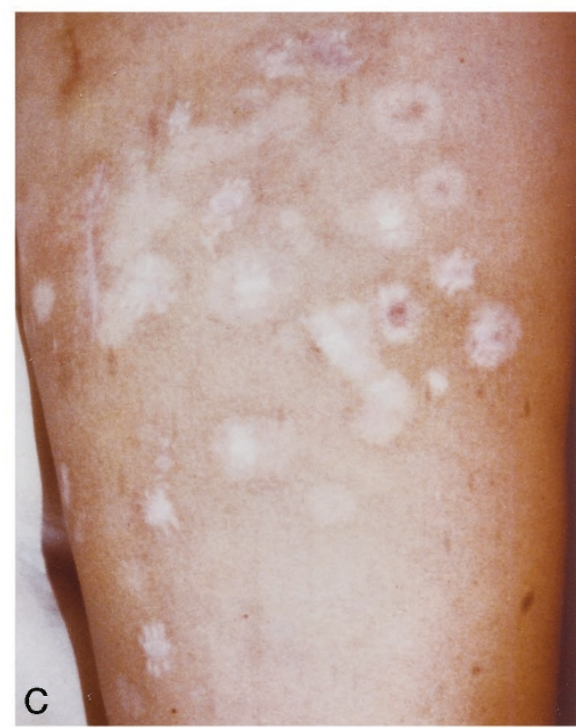

DAY +600

Figure 9. Patient 3, a 32-year-old female with extensive dermal metastases of the left thigh: anterior aspect before treatment (a), on day 81 (b), and on day 600,150 days posttreatment (c).

ever, the procedure is cumbersome and the half-life of the cytokine at the injection site is brief. In an effort to sustain local tumor levels, Robinson et $\mathrm{al}^{17}$ conducted a study of continuous i.t. GM-CSF infusion in eight patients with melanoma using a portable pump at doses of $10 \mu \mathrm{g} / 24$ hours over 8 weeks. One patient had a partial response. Frequent problems included local infection, blocked and/or dislodged catheters, sterile pus, and pain. Alternative approaches are being sought.

Reasoning that cytokine levels could be sustained more easily at the immunization site by local production rather than by local or systemic administration, tumor cells or fibroblasts genetically engineered to produce the molecule of interest were included in vaccine preparations. Some success has been achieved with this approach. ${ }^{3,4,18}$ Relevant to this report, Dranoff et $\mathrm{al}^{19}$ included GM-CSF in a panel of 10 molecules to compare their ability to enhance the immunogenicity of tumor cells. In the B16 melanoma model, nontransduced cells possessed little ability to stimulate systemic antitumor immunity. Immunizing C57BL/6 female mice with irradiated B16 melanoma cells expressing murine GM-CSF protected almost all animals against a subsequent challenge with $10^{6}$ nontransduced B16 cells. GMCSF-transduced B16 cells were dramatically more effective (10 of 10 protected) than wt B16 cells $(0$ of 10 protected) or cells transduced with genes for IL-1, $-2,-3$, $-4,-5$, or -6 , IFN- $\gamma$, tumor necrosis factor- $\alpha$, intercellular adhesion molecule-1, and CD2. Only IL-4- and IL-6transduced B16 cells afforded any protection ( 2 of 10 and 2 of 10 , respectively).

Whereas the studies cited above constitute a reasonable approach to proof of principle, translation to the

\section{PATIENT \#3}

\section{LESION 0 (UNTREATED)}

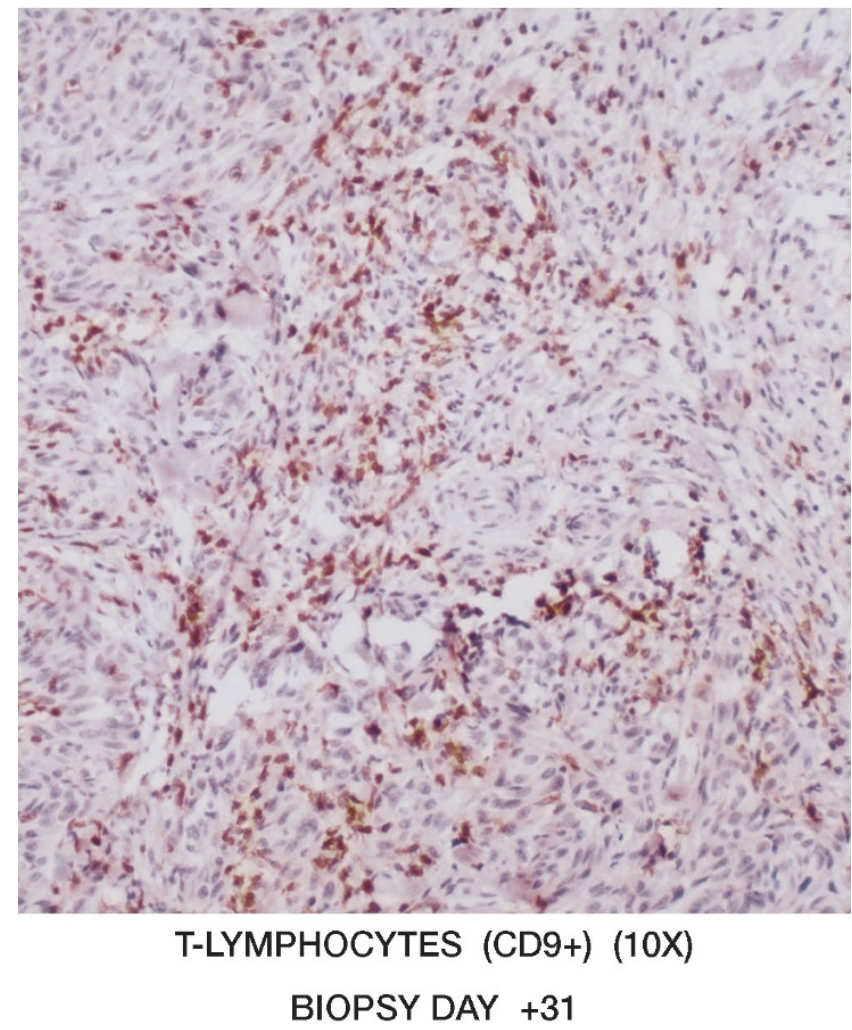

Figure 10. Patient 3 (lesion 0, day 31). An untreated dermal metastasis infiltrated by $\mathrm{CD}^{+}$cytotoxic/suppressor lymphocytes is shown. 
clinic has been technically difficult, and application is restricted to a small percentage of the candidate patient population. The requirement that autologous tumors be available, removed, transfected, etc., severely limits the number of eligible patients.

In the present study, RV was used to insert the GM-CSF gene into tumors in vivo so that the cytokine is produced in situ, thus enhancing tumor immunogenicity and the acquisition of immunity. This procedure does not require the harvest and processing of an autologous tumor or the reinjection of any additional tumors cells. Studies from other laboratories show the usefulness of focusing lymphokine or cytokine production at the immunization site. Our approach results in a similar focusing of immunoaugmenting factors at the tumor site without the previously cited limitations. RV may be beneficial for the treatment of tumors other than melanoma.

The attributes of various viral and nonviral vectors for gene transfer have been reviewed previously. ${ }^{18}$ This protocol explored the use of intralesional VV therapy to insert the GM-CSF gene into tumor cells in situ (in vivo). $\mathrm{VV}$ is well suited for this approach. ${ }^{20}$ It is highly infectious and will efficiently lyse infected tumor cells, thus directly reducing tumor burden. The wt virus alone will trigger a cytokine cascade and recruit helper $\mathrm{T}$ lymphocytes to the injection site. ${ }^{21}$ The virus has been used successfully for gene insertion in patients at risk for AIDs $^{22}$ and in colon cancer patients..$^{23}$ The large size of the virus allows it to serve as a carrier for multiple genes as needed. Encoded genes are delivered into and function in the cytoplasm of the host cell. The lytic property of the virus as well as the antivaccinia immune response of the host will prevent unrestricted (and potentially dangerous) cytokine production. However, we have demonstrated that local production of viral gene products can be continued by repeated injections of vaccinia. ${ }^{9}$ Most importantly, VV can be administered safely. ${ }^{24,25}$ Lee et $\mathrm{al}^{26}$ and $\mathrm{Ju}$ et $\mathrm{al}^{27}$ used an i.t. injection of GM-CSF gene-encoded recombinant VV to elicit a potent antitumor response in a murine melanoma model.

The favorable toxicity profiles of systemically administered GM-CSF and intracutaneously delivered wt VV have been well defined through years of clinical use. Nonetheless, safety concerns regarding the virulence of the RV and the i.t. delivery route in potentially immunocompromised patients prompted revaccination of study subjects as a precautionary measure. Antivaccinia immunity would limit virus proliferation. ${ }^{28}$ Consequently, this created a different problem. To maximize the opportunity to generate an immune response against weakly immunogenic tumor cells, we hypothesized that cytokine production needed to be maintained at treatment sites for a protracted period of $\geq 4$ weeks. However, in the face of antivaccinia immunity, the persistence of injected virus was almost certain to be $<1$ week. To circumvent this problem, a twice-weekly treatment schedule was adopted and was successful. Clinical evidence of infection at i.t. injection sites late in the course of therapy, the generation of $\mathrm{Ab}$ to the reporter gene product ( $\beta$-gal), the presence of mRNA for VAC GMCSF at 5 and 31 weeks after initiation of therapy, and eosinophilia at injection sites all support our conclusion that cytokine function could be maintained over a protracted period and seemingly indefinitely.

In designing the recombinant vaccinia, the reporter and cytokine genes were inserted so as to disrupt the continuity of the TK gene and attenuate the virulence of the virus. ${ }^{20}$ Our clinical impression was that the RV was less virulent than the wt virus when used similarly. ${ }^{9}$ This should permit the eventual elimination of the revaccination step, thus allowing more fulsome reactions at treatment sites, at least, early on.

Due to the lytic nature of the virus, regression of injected lesions was to be expected and did occur in five of seven patients. Encouragingly, uninjected regional dermal metastases regressed in four of four patients. We have yet to observe regression of bulky regional LNs, s.c. metastases, or distant disease. This will likely require further dose escalation not possible with the current formulation. Volume restricts dose escalation in smaller lesions, and limited supply precludes the saturation of larger lesions. A higher titered formulation is in production. Nonetheless, the clinical responses seen in this small group of seven patients are remarkable. Two patients (patients 3 and 7) have achieved seemingly durable complete remissions, albeit one patient (patient 3) with the assistance of surgery. This patient had exhausted all treatment modalities and was destined to die of her disease. She is alive and clinically free of disease 6 months after cessation of treatment. The dermal metastases on the scalp of patient 7 were not amenable to surgery or radiation therapy and were, in our experience, poorly responsive to systemic chemotherapy. He has achieved a complete response with minimal toxicity. Vaccinia/GM-CSF administered i.t. has proven remarkably effective in the treatment of regional dermal metastases, a clinical situation where little else has any durable effect.

This demonstration of efficacy along with reduced virulence justifies intervention earlier in the course of disease. For example, bulky primary tumors or palpable regional LN metastases could be injected with the vaccinia/GM-CSF RV prior to definitive surgery.

The approach lends itself to the treatment of a variety of other tumors, most notably intravesical treatment of patients who have failed bacillus Calmette-Guérin for superficial bladder cancer. In preclinical studies, we ${ }^{29}$ instilled influenza hemagglutinin and nuclear proteinencoding vaccinia recombinants intravesically in vaccinia-naive $\mathrm{CB} 7 \mathrm{BL} / 6$ mice bearing the MB49 tumor and demonstrated infection/transfection of tumor cells. Similar results were achieved with vaccinia-immune mice. Thus, systemic immunity to vaccinia, which would be expected to develop rapidly in bladder cancer patients as it did in the melanoma patients, did not prevent intravesical tumor infection/transfection. Early clinical trials with wt vaccinia have similarly demonstrated the ability to infect bladder mucosal/tumor cells in vaccinia-im- 


\section{PATIENT \#3 \\ UNTREATED LESION}
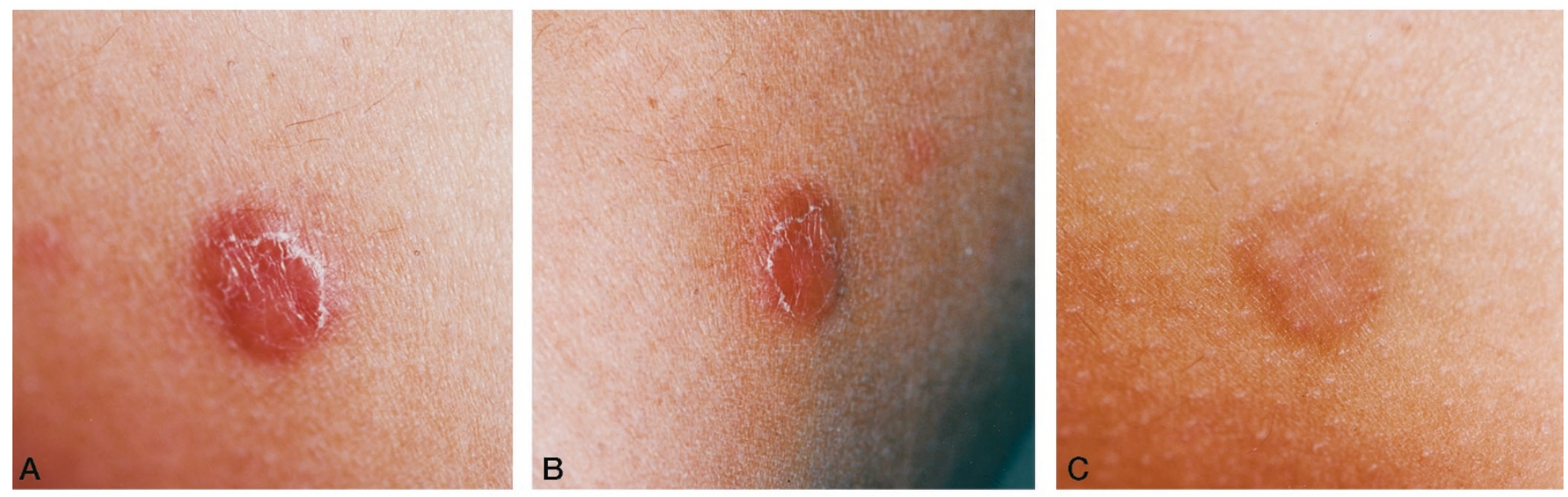

$\mathrm{DAY}+63$

DAY +81

DAY +160

Figure 11. Patient 3. Regression of an untreated signal dermal metastasis located lateral to the knee and upstream from the treated lesions is shown: day 63 (a), day 81 (b), and day 160 (c).

\section{PATIENT \#7}
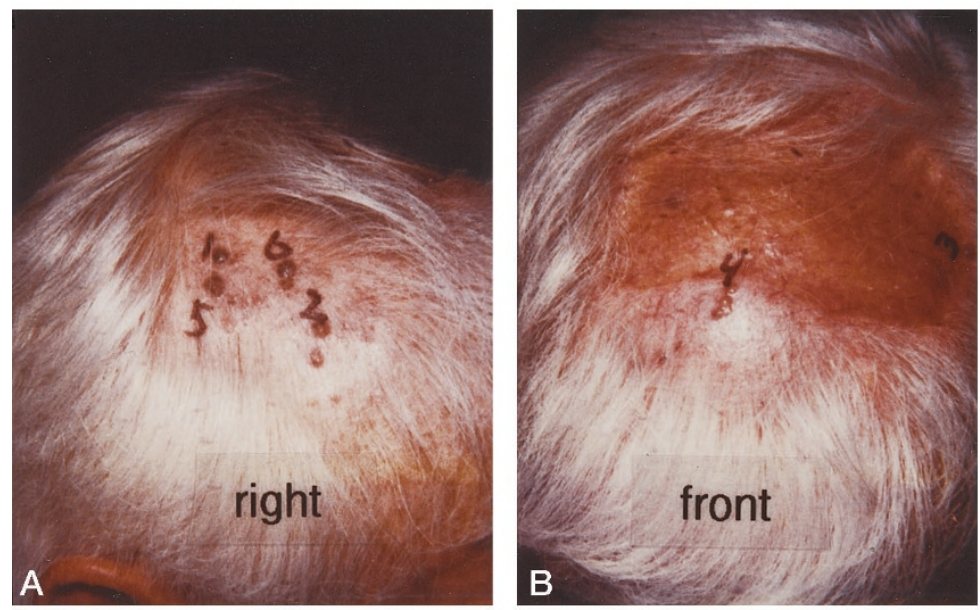

PRE-TREATMENT

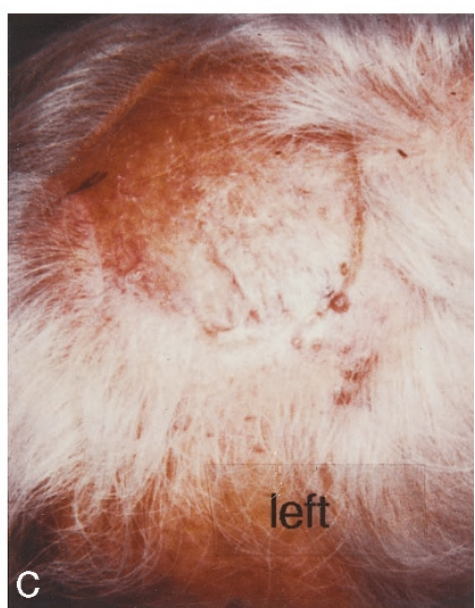

C

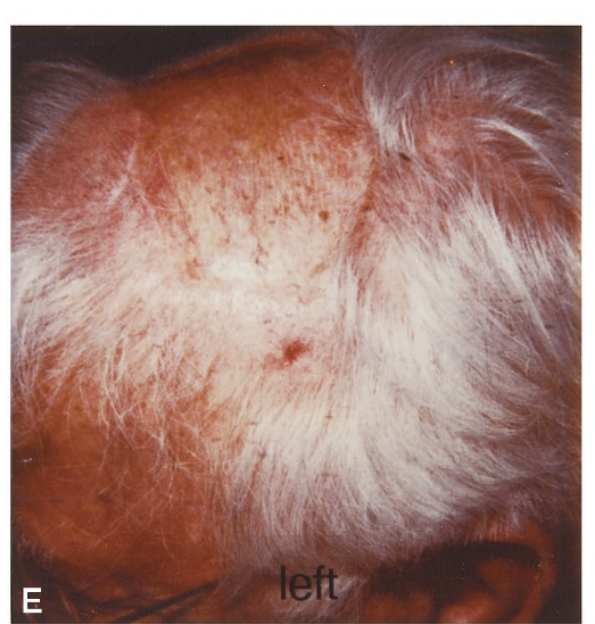

E

DAY 87 (56 DAYS POST-TREATMENT

Figure 12. Patient 7 , a 75 -year-old male with $\sim 24$, small, dermal metastases distributed about the perimeter of a grafted wide excision site of a primary scalp melanoma: a-c: pretreatment; d,e: day 87 . 
mune patients. ${ }^{30}$ Collectively, our data suggest that this approach will have application for a wide variety of cancers.

\section{ACKNOWLEDGMENTS}

We thank Debbie Cole for secretarial services and Margaret McCormick and Nicole Eckholm for expert technical assistance. The work performed by C.E.L. in constructing the vaccinia/GM-CSF recombinant was the basis of her Master's thesis. This work was supported by grants from the American Cancer Society (no. EDT-98 and no. IM-742), the National Institutes of Health (R21-CA69253, R01-CA42908, and R01CA59568), and the Nat Pincus Trust.

\section{REFERENCES}

1. Prehn RT, Main JM. Immunity to methylcholanthrene induced sarcomas. J Natl Cancer Inst. 1957;18:769-778.

2. Mastrangelo MJ, Sato T, Lattime EC, et al. Cellular vaccine therapies for cancer. In: Foon KA, Muss HB, eds. Biological and Hormonal Therapies of Cancer. Boston: Kluwer Academic Publishers; 1998:35-50.

3. Golumbek PT, Lazenby AJ, Levitsky HI, et al. Treatment of established renal cell cancer by tumor cells engineered to secrete interleukin-4. Science. 1991;254:713-716.

4. Mastrangelo MJ, Maguire HC Jr, Lattime EC. Gene therapy. In: Kurzrock R, Talpaz M, eds. Molecular Biology in Cancer Medicine, 2nd ed. London: Martin Dunitz; 1998: In press.

5. Mackett M, Smith GL, Moss B. General method for production and selection of infectious vaccinia virus recombinants expressing foreign genes. J Virol. 1984;49:857-864.

6. Chakrabarti S, Brechling K, Moss B. Vaccinia virus expression vector: co-expression of $\beta$-galactosidase provides visual screening of recombinant virus plaques. Mol Cell Biol. 1985;5:3403-3409.

7. Dookhan D, Kovatich AJ, Miettinen M. Non-enzymatic antigen retrieval in immunohistochemistry comparison between two antigen retrieval solutions and proteolytic digestion. Appl Immunohistochem. 1993;1:149-155.

8. Palazzo JP, Mercer WE, Kovatich AJ, et al. Immunohistochemical localization of $\mathrm{p} 21^{\text {WAFI/CIPI }}$ in normal, hyperplastic, and neoplastic uterine tissues. Hum Pathol. 1997;28:60-65.

9. Mastrangelo MJ, Maguire $\mathrm{HC} \mathrm{Jr}$, McCue P, et al. A pilot study demonstrating the feasibility of using intratumoral vaccinia injections as vector for gene transfer. Vaccine Res. 1995;4:58-69.

10. Kundig TM, Kalberer CP, Hengartner H, Zinkernagel RM. Vaccination with two different vaccinia recombinant viruses: long-term inhibition of secondary vaccination. Vaccine. 1993;11:1154-1158.

11. Clark SC, Kamen R. The human hematopoietic colonystimulating factors. Science. 1987;236:1229-1237.

12. Mehregan DR, Fransway AF, Edmonson JH, Leiferman KM. Cutaneous reactions to granulocyte-monocyte colony-stimulating factor. Arch Dermatol. 1992;128:1055-1059.

13. Jones T, Stern A, Lin R. Potential role of granulocytemacrophage colony-stimulating factor as vaccine adjuvant. Eur J Clin Microbiol Infect Dis. 1994;13:S47-S53.
14. Kwak LW, Young HA, Pennington RW, Weeks SD. Vaccination with syngeneic, lymphoma-derived immunoglobulin idiotype combined with granulocyte/macrophage colonystimulating factor primes mice for a protective T-cell response. Proc Natl Acad Sci USA. 1996;93:10972-10977.

15. Disis ML, Bernhard H, Shiota FM, et al. Granulocytemacrophage colony-stimulating factor: an effective adjuvant for protein and peptide-based vaccines. Blood. 1996; 88:202-210.

16. Harris DT, Matyas G, Mastrangelo MJ, et al. OncoVax-P vaccine: pilot studies in prostate cancer patients. Proc Am Soc Clin Oncol. 1998;17:428a.

17. Robinson BWS, Mukherjee SA, Davidson A, et al. Cytokine gene therapy or infusion as treatment for solid human cancer. J Immunother. 1998;21:211-217.

18. Mastrangelo MJ, Berd D, Nathan FE, Lattime EC. Gene therapy for human cancer: an essay for clinicians. Semin Oncol. 1996;23:4-21.

19. Dranoff G, Jaffee E, Lazenby A, et al. Vaccination with irradiated tumor cells engineered to secrete murine granulocyte-macrophage colony-stimulating factor stimulates potent, specific, and long-lasting anti-tumor immunity. Proc Natl Acad Sci USA. 1993;90:3539-3543.

20. Moss B. Vaccinia virus: a tool for research and development. Science. 1991;252:1660-1667.

21. Shimizu Y, Hasumi K, Masubuchi K, Okudaira Y. Immunotherapy of tumor-bearing mice utilizing virus help. Cancer Immunol Immunother. 1988;27:223-227.

22. Cooney EL, Collier AC, Greenberg PD, et al. Safety of and immunological response to a recombinant vaccinia virus vaccine expressing HIV envelope glycoprotein. Lancet. 1991;337:567-572.

23. Cole DJ, Wilson MC, Baron PL, et al. Phase I study of recombinant CEA vaccinia virus vaccine with post-vaccination CEA peptide challenge. Hum Gene Ther. 1996;7: 1381-1394.

24. Fenner F, Henderson DA, Anita I, et al. Smallpox and its Eradication. Geneva, Switzerland: World Health Organization; 1988.

25. Vaccinia (smallpox) vaccine: recommendations of the Immunization Practices Committee. MMWR. 1985;34:341-342.

26. Lee SS, Eisenlohr LC, McCue P, et al. In vivo gene therapy of murine tumor using recombinant vaccinia virus encoding GM-CSF. Proc Am Assoc Cancer Res. 1995;36:248.

27. Ju DW, Cao X, Acres B. Intratumoral injection of GMCSF gene encoded recombinant vaccinia virus elicits potent antitumor response in a murine melanoma model. Cancer Gene Ther. 1997;4:139-144.

28. Vanderplasschen A, Hollinshead M, Smith GL. Antibodies against vaccinia virus do not neutralize extracellular enveloped virus but do prevent virus release from infected cells and comet formation. J Gen Virol. 1997;78:2041-2048.

29. Lee SS, Eisenlohr LC, McCue PA, et al. Intravesical gene therapy: in vivo gene transfer using recombinant vaccinia virus vectors. Cancer Res. 1994;54:3325-3328.

30. Gomella LG, Mastrangelo MJ, Eisenlohr LC, et al. Phase I study of intravesical vaccinia virus as a vector for gene therapy of bladder cancer. Proc Am Assoc Cancer Res. 1997;38:9. 